Psychotherapy and Psychosomatics
Psychother Psychosom 2016;85:64

DOI: 10.1159/000441365
Published online: November 27, 2015

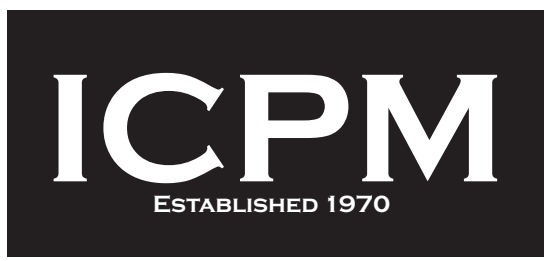

\title{
Report of the 23rd World Congress on Psychosomatic Medicine, Glasgow, UK, 2015
}

The World Congress on Psychosomatic Medicine is a worldwide, intercultural and interdisciplinary gathering for psychosomatic specialists. Its latest 23 rd edition was held on August 20-22, 2015, in Glasgow, Scotland. The theme of the congress was 'the psychosomatic factor in clinical practice', which attracted almost 400 multidisciplinary professional attendants from 21 countries. More than 300 abstracts were accepted and published as a supplement of Psychotherapy and Psychosomatics (IF =9.20). They will all be listed in Web of Science, which provides a permanent track of the unique experience of the congress. At this 3-day congress, there were 2 plenary lectures, 6 update lectures, 18 symposia, 35 workshops, and 5 clinical case presentations. The presentations covered wide topics across research and clinical aspects of psychosomatic medicine, psychotherapy, organizational and teaching, philosophy, and many others. It turned out not only to provide a high-quality opportunity for international professionals focused on psychosomatic medicine to establish collaborative relationships and friendship, but also to present and exchange new developments spanning from methodology to clinical aspects of psychosomatic medicine.
Well-known experts were present at the opening and closing ceremonies delivering speeches to celebrate and witness the magnificent event. These included Tom Wise, the current President of ICPM, Chiharu Kubo, the Past President of ICPM, Antonio Barbosa, the President Elect of ICPM, Giovanni Fava, the Editor of Psychotherapy and Psychosomatics, and Mike Gow, the Local Organizer of the Congress. There were poster awards which were aimed at young researchers presenting posters on advanced research on psychosomatic medicine.

During the congress the new Executive Board was elected:

Antonio Barbosa (Portugal), President Tom Wise (USA), Past President Fiammetta Cosci (Italy), President Elect Eva-Lotta Brakemeier (Germany), Secretary Kyung Bong Koh (South Korea), Treasurer

Fiammetta Cosci

Secretary on the International College of Psychosomatic Medicine (2011-2015) 